\title{
Amiodarone-induced thyroid dysfunction: brand-name versus generic formulations
}

\author{
Meytal A. Tsadok PhD, Cynthia A. Jackevicius PharmD MSc, Elham Rahme PhD, Vidal Essebag MD PhD, \\ Mark J. Eisenberg MD MPH, Karin H. Humphries DSc, Jack V. Tu MD PhD, Hassan Behlouli PhD, \\ Jennifer Joo BS, Louise Pilote MD PhD
}

See related commentary by Kesselheim at www.cmaj.ca/lookup/doi/10.1503/cmaj.110808; see also practice article by Mackenzie and colleagues at www.cmaj.ca/lookup/doi/10.1503/cmaj.100351.

\begin{abstract}
Background: Amiodarone is associated with dysfunction of the thyroid. Concerns have arisen regarding the potential for adverse effects with generic formulations of amiodarone. We evaluated and compared the risk of thyroid dysfunction between patients using brand-name versus generic formulations of amiodarone and identified risk factors for thyroid dysfunction.
\end{abstract}

Methods: We conducted a retrospective cohort study of patients with atrial fibrillation aged 66 years and older. We used administrative databases that linked information on demographics and clinical characteristics, claims for prescription drugs and discharges from hospital. We estimated thyroid dysfunction using person-year incidence.

Results: Of the 60220 patients in the cohort, $2804(4.7 \%)$ used the brand-name formulation of amiodarone and $6278(10.4 \%)$ used the generic formulation. Baseline characteristics between these two groups were comparable. The median maintenance dose of amiodarone was $200 \mathrm{mg} / \mathrm{d}$ for both groups. The total incidence rate for thyroid dysfunction was 14.1 per 100 person-years for both formulations. The mean time to clinical dysfunction of the thyroid was 4.32 years for the brand-name formulation and 4.09 years for the generic formulation. In a multivariate analysis, there was no significant difference in the incidence rates of thyroid dysfunction between the generic and brand formulations (hazard ratio 0.97, 95\% confidence interval 0.87-1.08). Factors associated with an increased risk of thyroid dysfunction were being a woman, increasing age and having chronic obstructive pulmonary disease.

Interpretation: In this population-based study, we saw no difference between brand-name and generic formulations of amiodarone in terms of incidence of thyroid dysfunction.
Competing interests: Meytal Tsadok, Cynthia Jackevicius and Vidal Essebag have received grants from the Canadian Institutes of Health Research. Vidal Essebag is a consultant for Sanofi Aventis and Boehringer Ingelheim and has received payment for lectures from Sanofi Aventis, Boehringer Ingelheim and Medtronic.

No other competing interests were declared.

This article has been peer reviewed.

Correspondence to: Dr. Louise Pilote, louise.pilote@mcgill.ca

CMAJ 2011. DOI:10.1503 /cmaj.101800
$\mathrm{T}$ he antiarrhythmic agent amiodarone is considered the most effective drug for controlling rhythm in atrial fibrillation..$^{1,2}$ Amiodarone's effects on the function of the thyroid have long been recognized and range from subclinical to clinically apparent hypo- or hyperthyroidism. ${ }^{3.4}$ The proportions of patients with amiodarone-induced dysfunction of the thyroid have been estimated at $0.6 \%-20.8 \%$ (thyrotoxicosis) and 3.3\%-25.8\% (hypothyroidism).$^{5-8}$ However, the incidence of thyroid dysfunction has not been estimated previously in a large-scale, population-based cohort.

Amiodarone was first available in Canada as Cordarone. Generic products have since become widely used instead of brand-name formulations to help control medication-related costs. ${ }^{9}$ Government regulations allow a generic formulation to be used if it is considered bioequivalent to the brand-name formulation. ${ }^{10}$ Because amiodarone has a narrow therapeutic index, a complex phar- macokinetic profile and important interactions with other drugs, concerns have been raised that generic substitution may lead to loss of efficacy or an increase in adverse events. ${ }^{11-15}$

To date, there is no information on the varying effects of brand-name versus generic formulations of amiodarone on the incidence of thyroid dysfunction. In this study, we aim to compare the population-based incidence of thyroid dysfunction among patients with atrial fibrillation who were given prescriptions for brand-name formulations of amiodarone with the incidence among patients given generic formulations of the drug. We also identify risk factors associated with thyroid dysfunction.

\section{Methods}

\section{Study cohort}

We conducted a retrospective cohort study using 
administrative data. Patients included in the cohort were 66 years of age or older and had been discharged from hospital with a diagnosis of atrial fibrillation between Jan. 1, 1998, and Mar. 31, 2007 (the index event).

Patients were selected for inclusion in the cohort using the hospital discharge abstract database Med-Echo, which contains information on inpatient diagnoses and comorbidities. Using patients' encrypted health insurance numbers, we linked these data to the Régie de l'Assurance Maladie du Québec, the provincial database containing information on all outpatient prescriptions given to patients 65 years of age or older, as well as all inpatient and outpatient diagnostic and therapeutic procedures in Québec. Outpatient medication formulations were identified using the drug identification number, and the prescription claims database provided information on the quantities prescribed. Prescription claims databases have been found to be a reliable source of information on filled prescriptions. ${ }^{16}$

Participants were identified for possible inclusion in the study based on a primary or secondary in-hospital diagnosis of atrial fibrillation (i.e., the clinical modification of the International Classification of Diseases, 9th revision [ICD-CM9], codes 427.3, 427.31 or 427.32, and the International Statistical Classification of Diseases and Related Health Problems, 10th revision [ICD-10], code I48). We excluded patients who had atrial fibrillation that was listed as a postadmission complication, patients who had a history of surgery and perioperative atrial fibrillation, and patients with hyperthyroidism or thyrotoxicosis within the 12 months preceding the index event. We also excluded patients who had used amiodarone during the year preceding the index event, patients who did not have a valid health card number, patients who were residents of chronic care facilities and patients who were older than 105 years. For patients with records showing more than one diagnostic code for atrial fibrillation, the first date of diagnosis was defined as the date of entry into the cohort. Baseline characteristics, comorbidities and $\mathrm{CHADS}_{2}$ scores (congestive heart failure, hypertension, age $\geq 75 \mathrm{yr}$, diabetes mellitus and previous stroke or transient ischemic attack $)^{17}$ were obtained from the previously mentioned sources of data. Socioeconomic status was determined indirectly using the mean family income of patients' neighbourhoods (derived from responses to the 2001 Census of Canada) according to the first three digits of their postal code at the time of admission to hospital.

This study received institutional review board approval from the McGill University Faculty of Medicine (study number A05-M79-08B).

\section{Definition of exposure}

Participants were divided into two groups, patients who used brand-name amiodarone and patients who used a generic formulation, based on the first prescription they filled after being discharged from hospital. When a patient did not have a subsequent claim for amiodarone within 60 days of the end date of their last filled prescription, they were considered to have stopped taking the drug. Patients were further divided into groups of low $(\leq 200 \mathrm{mg} / \mathrm{d})$, intermediate (> 200 and $\leq 400 \mathrm{mg} / \mathrm{d})$ or high $(>400 \mathrm{mg} / \mathrm{d})$ maintenance doses of amiodarone based on information from the prescription claims database between 61 and 99 days after their discharge from hospital. For patients who did not refill their prescription during this period, the initial prescription dose after discharge was used.

\section{Outcome}

The primary study outcome was defined as admission to hospital or an outpatient physician claim for a principal or secondary diagnosis of thyroid dysfunction (ICD-9-CM codes 242 [hyperthyroidism], 243 and 244 [hypothyroidism] or ICD10 codes E05 [hyperthyroidism], E02 or E03 [hypothyroidism]), or a claim for a filled prescription for a thyroid medication (propylthiouracil, methimazole, levothyroxine or liothyronine). Thyroid dysfunction was considered to be related to amiodarone exposure only if it occurred more than 2.5 months after the date of a claim for an amiodarone prescription, which accounted for the approximate time needed for amiodarone to influence the functioning of the patient's thyroid.

\section{Statistical analysis}

Descriptive statistics were used to compare baseline characteristics and patterns of amiodarone use between groups (brand-name v. generic formulations).

Continuous data (age, annual income, $\mathrm{CHADS}_{2}$ score and length of stay in hospital) were compared using Student $t$ tests, and categorical data (sex, comorbidities and primary treating physician) were compared using $\chi^{2}$ tests. We estimated the proportions of thyroid dysfunction for the patients who used brand-name versus generic amiodarone. We calculated the incidence of thyroid dysfunction per 100 person-years as the number of subjects with thyroid dysfunction divided by the sum of observation years for all subjects who were exposed to any formulation of amiodarone. Follow-up for each participant was censored after the first diagnosis of thyroid dysfunction, when the patient died, at the end of the study period or when the patient stopped treatment or switched between formulations, whichever happened first. If patients switched from 
one formulation to the other, only the first prescribed formulation was used in our analyses.

For time-to-event analyses, rates of thyroid dysfunction were estimated by Kaplan-Meier methods and compared using the log-rank test. We used a multivariable Cox proportional hazards model to estimate hazard ratios (HRs) with $95 \%$ confidence intervals (CIs) for thyroid dysfunction between the brand-name and generic groups, accounting for potential confounders. Potential risk factors for thy- roid dysfunction were grouped as follows: dose of amiodarone, patient demographics (sex, age, family income) and baseline comorbidities present during the year before admission to hospital for atrial fibrillation (identified from the hospital database).

\section{Results}

Of the 60220 patients included in the cohort, $2804(4.7 \%)$ used the brand-name formulation

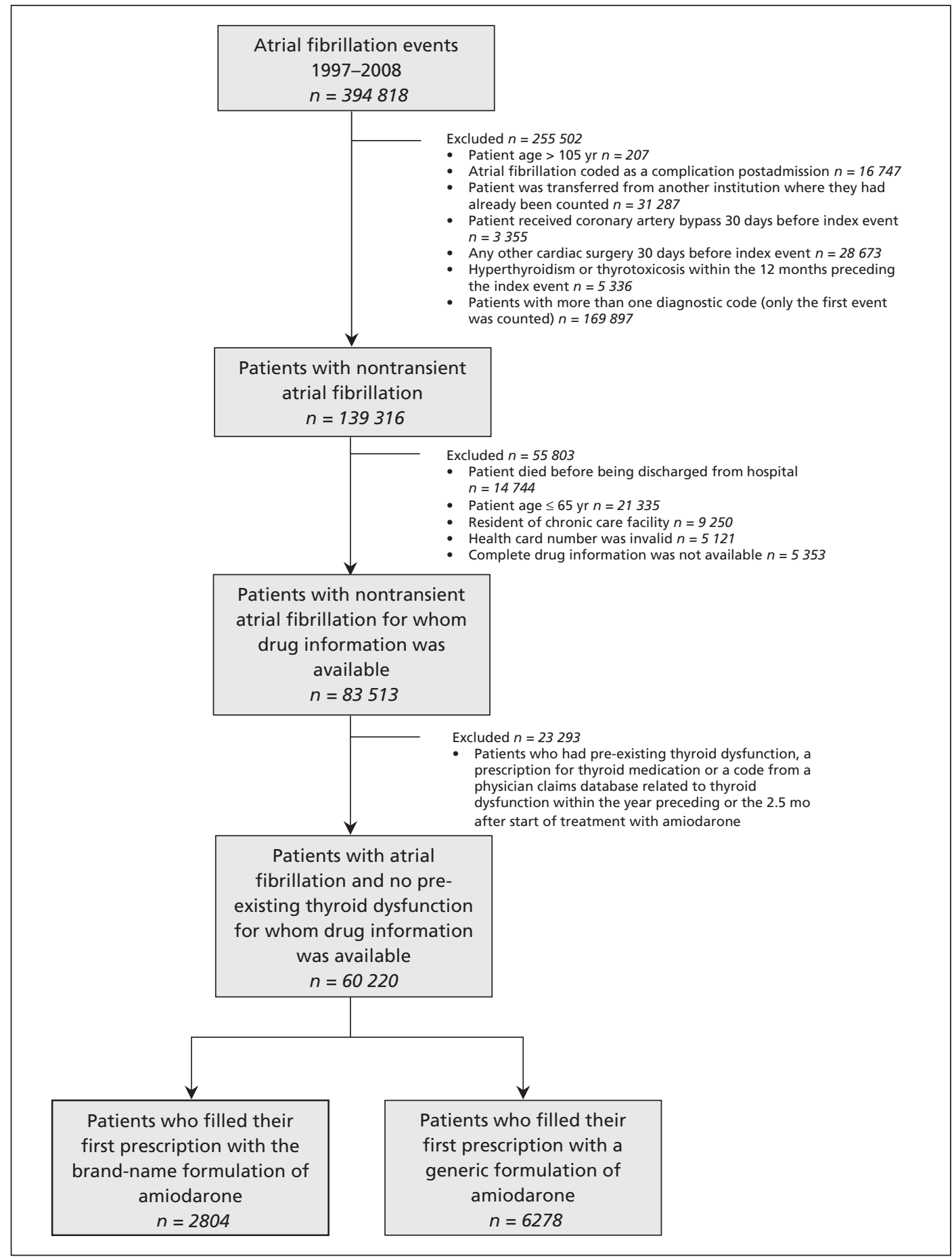

Figure 1: Flow chart of criteria used to select participants for the study. 
(from one manufacturer) and 6278 (10.4\%) used the generic formulation (from eight different manufacturers) as the first prescription filled after discharge from hospital (Figure 1). The mean age of patients in the cohort was 76.9 years and $53.7 \%$ were men. Baseline characteristics were similar between the groups using brand-name and generic formulations (Table 1), including mean $\mathrm{CHADS}_{2}$ scores $(1.7 \pm 1.1$ for the brand-name group and $1.8 \pm 1.1$ for the generic group). Among the patients in the brand-name group, the proportions of patients with hypertension $(52.0 \%$ v. $59.2 \%)$ and hyperlipidemia $(23.4 \%$ v. $28.6 \%)$ were lower

\begin{tabular}{|c|c|c|c|}
\hline Characteristic & $\begin{array}{c}\text { Brand name } \\
(n=2804)\end{array}$ & $\begin{array}{l}\text { Generic } \\
(n=6278)\end{array}$ & $p$ value* \\
\hline Age, $y r$, mean $\pm S D$ & $76.7 \pm 6.3$ & $77.0 \pm 6.4$ & 0.03 \\
\hline Men, \% & 54.0 & 53.5 & 0.65 \\
\hline $\begin{array}{l}\text { Annual family income, } \$ \\
\text { mean } \pm \text { SD }\end{array}$ & $\begin{array}{c}49456.40 \\
\pm 10860.50\end{array}$ & $\begin{array}{c}48634.20 \\
\pm 10653.00\end{array}$ & $<0.001$ \\
\hline \multicolumn{4}{|l|}{$\begin{array}{l}\text { Comorbidities in the } \\
\text { year preceding } \\
\text { admission to hospital, \% }\end{array}$} \\
\hline Hypertension & 52.0 & 59.2 & $<0.001$ \\
\hline $\begin{array}{l}\text { Coronary artery } \\
\text { disease }\end{array}$ & 51.6 & 52.2 & 0.63 \\
\hline Heart failure & 34.0 & 33.0 & 0.36 \\
\hline COPD & 28.7 & 28.0 & 0.50 \\
\hline Valvular disease & 24.9 & 22.0 & 0.003 \\
\hline Hyperlipidemia & 23.4 & 28.6 & $<0.001$ \\
\hline Diabetes mellitus & 23.3 & 23.4 & 0.94 \\
\hline Acute MI & 22.4 & 23.8 & 0.16 \\
\hline Chronic kidney disease & 13.8 & 16.5 & $<0.001$ \\
\hline $\begin{array}{l}\text { Ischemic } \\
\text { cerebrovascular } \\
\text { disease (including TIA } \\
\text { and retinal infarct) }\end{array}$ & 5.3 & 5.4 & 0.89 \\
\hline Bleeding events & 4.5 & 5.2 & 0.20 \\
\hline Liver disease & 2.4 & 2.5 & 0.86 \\
\hline $\begin{array}{l}\text { CHADS }_{2} \text { score } 1 \text { yr before } \\
\text { admission, mean } \pm \text { SD }\end{array}$ & $1.7 \pm 1.1$ & $1.8 \pm 1.1$ & 0.006 \\
\hline \multicolumn{4}{|l|}{$\begin{array}{l}\text { Primary treating } \\
\text { physician at hospital, \% }\end{array}$} \\
\hline Generalist & 43.9 & 46.1 & 0.05 \\
\hline Internist & 8.4 & 8.2 & 0.75 \\
\hline Cardiologist & 37.1 & 33.8 & 0.002 \\
\hline $\begin{array}{l}\text { Length of stay in } \\
\text { hospital, } d \text {, mean } \pm \text { SD }\end{array}$ & $12.1 \pm 15.4$ & $12.5 \pm 16.7$ & 0.34 \\
\hline \multicolumn{4}{|c|}{$\begin{array}{l}\text { Note: } \mathrm{CHADS}_{2}=\text { congestive heart failure, hypertension, age } \geq 75 \text { years, diabetes mellitus and } \\
\text { previous stroke or TIA, COPD = chronic obstructive pulmonary disease, } \mathrm{MI}=\text { myocardial } \\
\text { infarction, } \mathrm{SD}=\text { standard deviation, TIA }=\text { transient ischemic attack. } \\
{ }^{*} \text { Continuous data were compared using Student } t \text { tests, and categorical data were comparec } \\
\text { using } \chi^{2} \text { tests. }\end{array}$} \\
\hline
\end{tabular}

than the proportions seen in the generic group. Mean annual family income was higher among patients in the brand-name group ( $\$ 49456 / y r)$ than among patients in the generic group (\$48 634/yr). For both groups, the mean length of stay in hospital after the index event was less than two weeks, and treatment with amiodarone started immediately after discharge from hospital.

The median maintenance dose of amiodarone was $200 \mathrm{mg} / \mathrm{d}$ for both groups (Table 2). Patients taking the brand-name formulation were more likely to stop treatment $(54.6 \%)$ than patients taking the generic formulation (43.8\%). In addition, $44.6 \%$ of patients given the brand-name formulation switched to the generic formulation; only $4.0 \%$ of patients who started treatment with the generic formulation switched to the brandname drug (Table 2).

The mean length of follow-up for the patients in the brand-name group was 1.2 years, during which time $16.8 \%$ experienced thyroid dysfunction; for the patients in the generic group, $17.9 \%$ experienced thyroid dysfunction over a mean follow-up of 1.3 years (Table 3 ). For both groups, most instances of thyroid dysfunction were hypothyroidism (15.8\% for the brand-name group, $16.6 \%$ for the generic group). Of the patients using the brand-name formulation, $2.6 \%$ had hyperthyroidism, and the corresponding rate among patients using the generic formulation was $2.5 \%$. The incidence rate for thyroid dysfunction was estimated at 14.1 per 100 person-years, similar for both formulations (Table 3). The incidence rates for hypothyroidism and hyperthyroidism per 100 person-years were comparable between brandname and generic formulations (Table 3), with hypothyroidism occurring more commonly. The mean time to onset of thyroid dysfunction among patients who developed it was $4.32 \pm 0.08$ years for those taking the brand-name drug and $4.09 \pm$ 0.05 years for those taking the generic formulation (Figure 2), with no statistically significant differences between formulations. A subgroup analysis showed no statistically significant differences in the rates of thyroid dysfunction between the most commonly used generic formulations (data not shown).

After adjusting for potential confounders (as listed in Table 4), we saw no statistically significant difference in the incidence of thyroid dysfunction among patients who used the generic versus brand-name formulations of amiodarone (HR $0.98,95 \%$ CI $0.88-1.09, p=0.69$ ). A significantly increased risk of thyroid dysfunction was associated with being a woman, increasing age and a history of chronic obstructive pulmonary disease (COPD) (Table 4).

When we repeated our analysis using only the prescription claims definition of thyroid dysfunc- 
tion, we found no difference in the incidence rates between brand-name and generic formulations of amiodarone (HR 0.95, 95\% CI 0.84-1.06), which was consistent with our primary results that used our comprehensive definition of thyroid dysfunction.

We used sensitivity analyses to evaluate our method for detecting thyroid dysfunction (i.e., for determining the primary study outcome). We compared rates of thyroid dysfunction among people who used amiodarone $(n=9082)$ and people who did not $(n=51$ 138). Among people who used amiodarone, the rate of thyroid dysfunction was 14.34 per 100 person-years; the corresponding rate among people who did not take amiodarone was 6.77 per 100 person-years. These results show that our method discriminated well between people who used amiodarone and people who did not.

\section{Interpretation}

In this retrospective population-based cohort study, thyroid dysfunction was estimated to occur at a rate of 14.1 per 100 person-years among patients with atrial fibrillation who were receiving treatment with amiodarone. This rate is in accordance with the rates seen in previous prospective studies and clinical trials $(10 \%-20 \%$ for amiodarone-induced thyrotoxicosis or hypothyroidism). ${ }^{18,19}$ Consistent with other studies, most of the thyroid dysfunction we saw was related to hypothyroidism ( $16.3 \%$ overall), rather than to hyperthyroidism $(2.5 \%)$. $^{7,18,19}$ Given that thyroid dysfunction affects almost one in five patients taking amiodarone, patients with atrial fibrillation should be made aware of this risk when they start treatment with amiodarone to ensure that any symptoms are recognized and reported to their clinicians as early as possible for monitoring, timely follow-up and possible treatment.

The mean time to onset of thyroid dysfunction in our study was approximately four years, which is longer than the length of time reported in other studies. ${ }^{5,20}$ Given that our study is population-based, the longer onset may reflect the real-world setting, in which the diagnosis of thyroid dysfunction may take more time.

Generic drugs play an important role in most private and all government-run drug benefit plans, since generic manufacturers are able to offer products at prices lower than those of the brand-name alternatives. Regulations from the US Food and Drug Administration and Health Canada allow substitution with a generic formulation if it is considered to be bioequivalent with the brand-name version; that is, the $90 \%$ CIs for the area under the curve of the plasma concentration for the generic product must fall within $80 \%-125 \%$ of the plasma concentration for the brand-name formulation. Beyond bioequivalence, similar clinical outcomes for efficacy and toxicity of brand-name and generic products is important for clinicians and patients.

Although evidence does not support the idea that brand-name drugs used in the treatment of cardiovascular diseases are superior to generic drugs, a substantial number of editorials counsel against interchangeability. ${ }^{21}$ These concerns have been expressed specifically with formulations of amiodarone, ${ }^{11-15,22,23}$ based on data from case reports $^{14,15}$ and an in vitro study. ${ }^{23}$

Table 2: Patterns of use for brand-name and generic formulations of amiodarone

\begin{tabular}{|c|c|c|c|}
\hline Variable & $\begin{array}{l}\text { Brand name } \\
(n=2804)\end{array}$ & $\begin{array}{l}\text { Generic } \\
(n=6278)\end{array}$ & $p$ value* \\
\hline $\begin{array}{l}\text { Daily dose of amiodarone, } \\
\text { mg, median (IQR) }\end{array}$ & $200(200-300)$ & $200(200-233)$ & 0.44 \\
\hline Low dose ( $\leq 200 \mathrm{mg}$ ), \% & 71.7 & 74.4 & 0.007 \\
\hline $\begin{array}{l}\text { Intermediate dose } \\
(>200 \mathrm{mg}, \leq 400 \mathrm{mg}), \%\end{array}$ & 18.2 & 15.7 & 0.003 \\
\hline High dose (> $400 \mathrm{mg}), \%$ & 10.1 & 9.9 & 0.73 \\
\hline $\begin{array}{l}\text { Time between discharge and } \\
\text { filling of first prescription, } d \text {, } \\
\text { mean (IQR) }\end{array}$ & $0(0-82)$ & $1(0-236)$ & $<0.001$ \\
\hline $\begin{array}{l}\text { Patients who stopped taking } \\
\text { amiodarone, } \%\end{array}$ & 54. 6 & 43.8 & $<0.001$ \\
\hline $\begin{array}{l}\text { Patients who switched } \\
\text { formulations, \% }\end{array}$ & 44.6 & 4.0 & $<0.001$ \\
\hline \multicolumn{4}{|c|}{$\begin{array}{l}\text { Note: IQR = interquartile range. } \\
{ }^{*} \text { Continuous data were compared using Student } t \text { tests, and categorical data were compared } \\
\text { using } \chi^{2} \text { tests. }\end{array}$} \\
\hline
\end{tabular}

Table 3: Outcomes related to thyroid dysfunction among patients using brand-name and generic formulations of amiodarone

\begin{tabular}{|c|c|c|c|}
\hline Variable or outcome & $\begin{array}{l}\text { Brand name } \\
(n=2804)\end{array}$ & $\begin{array}{l}\text { Generic } \\
(n=6278)\end{array}$ & $p$ value* \\
\hline $\begin{array}{l}\text { Length of follow-up, } y, \\
\text { mean } \pm S D\end{array}$ & $1.2 \pm 0.2$ & $1.3 \pm 0.2$ & 0.008 \\
\hline $\begin{array}{l}\text { Patients with disorders of } \\
\text { the thyroid, } \%\end{array}$ & 16.8 & 17.9 & 0.22 \\
\hline Hypothyroid ism, \%† & 15.8 & 16.6 & 0.35 \\
\hline Hyperthyroidism, \%† & 2.6 & 2.5 & 0.75 \\
\hline $\begin{array}{l}\text { Total rate of thyroid } \\
\text { dysfunction, per } 100 \\
\text { person-years }\end{array}$ & 14.1 & 14.1 & 0.98 \\
\hline $\begin{array}{l}\text { Hypothyroidism, } \\
\text { per } 100 \text { person-years } t\end{array}$ & 13.1 & 12.8 & 0.77 \\
\hline $\begin{array}{l}\text { Hyperthyroidism, } \\
\text { per } 100 \text { person-years }\end{array}$ & 1.9 & 1.6 & 0.40 \\
\hline
\end{tabular}

Note: $\mathrm{SD}=$ standard deviation

*Continuous data were compared using Student $t$ tests, and categorical data were compared using $\chi^{2}$ tests.

tSome patients had both hypothyroidism and hyperthyroidism. 
We found no difference in the incidence of thyroid dysfunction between generic and brand-name formulations. It is important to note that we only investigated the adverse effect of amiodarone with

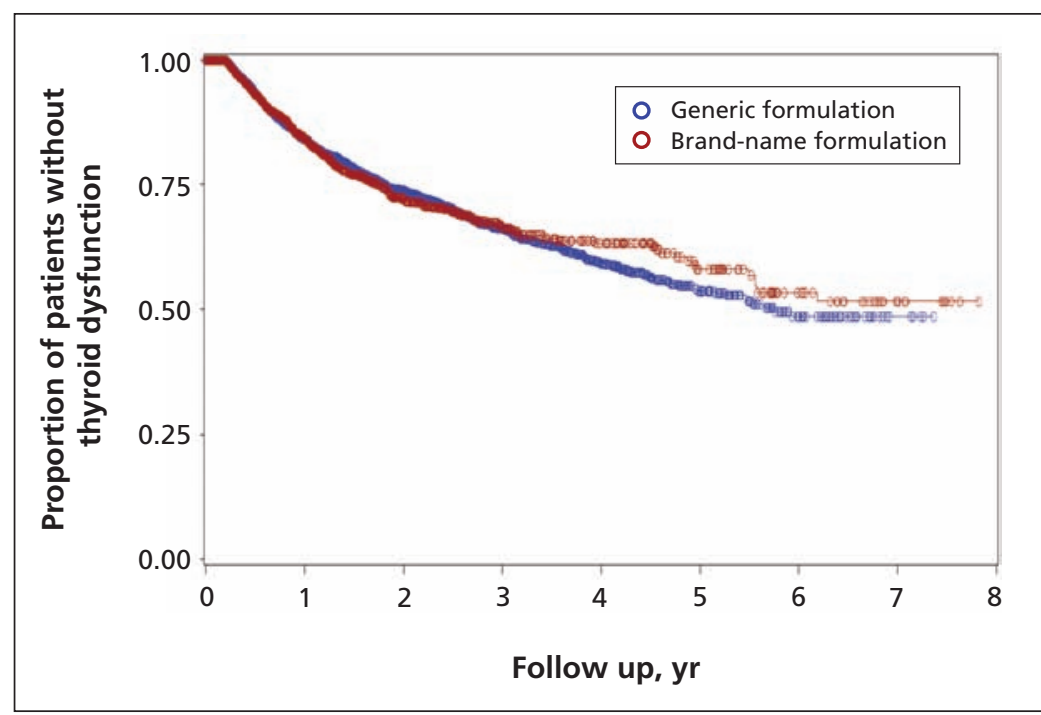

Figure 2: Proportion of patients without thyroid dysfunction according to use of brand-name versus generic formulations of amiodarone over eight years of follow-up. Log-rank test $\boldsymbol{p}=\mathbf{0 . 8 9}$.

Table 4: Factors associated with thyroid dysfunction

\begin{tabular}{|lcr|}
\hline Variable & Adjusted HR (95\% Cl) & $p$ value \\
\hline $\begin{array}{l}\text { Taking a generic formulation of } \\
\text { amiodarone (v. brand name) }\end{array}$ & $0.98(0.88-1.09)$ & 0.69 \\
\hline $\begin{array}{l}\text { Strength of first dose (v. low) } \\
\quad \text { Intermediate }\end{array}$ & $1.00(0.89-1.14)$ & 0.95 \\
\hline High & $1.11(0.97-1.26)$ & 0.12 \\
\hline Being a man & $0.76(0.68-0.84)$ & $<0.01$ \\
\hline $\begin{array}{l}\text { Age at admission to hospital for } \\
\text { index event, per yr }\end{array}$ & $1.01(1.00-1.02)$ & 0.02 \\
\hline Median family income, per \$ & $1.00(0.99-1.00)$ & 0.06 \\
\hline $\begin{array}{l}\text { Baseline comorbidities in the year } \\
\text { preceding the index event }\end{array}$ & $1.06(0.95-1.17)$ & 0.31 \\
\hline Hypertension & $1.13(1.00-1.27)$ & 0.05 \\
\hline Coronary artery disease & $1.09(0.98-1.22)$ & 0.11 \\
\hline Heart failure & $1.21(1.08-1.35)$ & $<0.01$ \\
\hline COPD & $0.94(0.83-1.06)$ & 0.31 \\
\hline $\begin{array}{l}\text { Valvular disease } \\
\text { Hyperlipidemia }\end{array}$ & $1.07(0.95-1.20)$ & 0.27 \\
\hline $\begin{array}{l}\text { Diabetes } \\
\text { Acute myocardial infarction }\end{array}$ & $1.03(0.91-1.17)$ & 0.61 \\
\hline $\begin{array}{l}\text { Chronic renal failure } \\
\text { Ischemic cerebrovascular disease } \\
\text { (including TIA and retinal infarct) }\end{array}$ & $0.91(0.79-1.05)$ & 0.19 \\
\hline Any bleeding event & $1.10(0.95-1.27)$ & 0.21 \\
\hline $\begin{array}{l}\text { Liver disease } \\
\text { ratio, TIA = transient ischemic attack. }\end{array}$ & $0.82(0.62-1.10)$ & 0.10 \\
\hline
\end{tabular}

regard to thyroid dysfunction, rather than the differences in efficacy or other adverse effects between brand-name and generic formulations.

Risk factors for amiodarone-induced thyroid dysfunction seen in our cohort were being a woman, older age, and a history of COPD. Previous studies have shown that being a woman and increased age are known risk factors for amiodarone-induced thyroid dysfunction. ${ }^{24-26} \mathrm{Sev}$ eral studies have shown changes in the levels of thyroid hormones among patients with COPD, especially patients with severe disease. ${ }^{27-29}$ It is possible that people with a history of COPD have a predisposition to changes in the function of their thyroid glands, which may be amplified by treatment with amiodarone. Clinicians should consider differential monitoring protocols for this high-risk group. If treatment with amiodarone is chosen for these patients, we recommend extra vigilance in monitoring parameters such as levels of thyroidstimulating hormone before treatment begins and every three to six months thereafter.

Our results suggest that the maintenance dose of amiodarone is not a significant risk factor for thyroid dysfunction.

\section{Limitations}

The main limitation of our study is that our database does not contain information on levels of thyroid hormones. Therefore, we could not detect subclinical thyroid dysfunction and could not classify the severity of the disease outcome. In addition, our study was restricted to older patients owing to the availability of data on prescription claims. However, given that amiodarone is primarily used in atrial fibrillation, which mainly affects older patients, the age restriction may be of less concern.

A further limitation was the possibility of undercoding. To overcome this, we used a broad definition of thyroid dysfunction that included data on prescription claims for thyroid medications. However, because medications are mainly prescribed for clinical thyroid dysfunction, it is possible that we identified only patients with more severe and clinically apparent thyroid dysfunction. Our internal evaluation of the method used to detect thyroid dysfunction suggests that it is both sensitive and specific. However, it is possible that our method was not powerful enough to detect a difference in the risk of thyroid dysfunction between brand-name and generic formulations.

Given that a considerable number of patients (25.2\%) stopped taking amiodarone within three months of being discharged from hospital and that the initial "loading" dose for these patients was considered instead of the "maintenance" dose, our estimation of dose-related associations may be partially biased. 
As an observational cohort study, we foresee the greatest potential limitation to be selection bias. Factors that influence which formulations are given to certain patients may also be related to the subsequent outcomes these patients experience. Such bias is unlikely, as the main reason for patients taking generic amiodarone is its availability over time and not its differential physiologic function. As data on patient weight or body mass index were not available in our databases, we were unable to adjust our multivariate analysis for these covariates, although they are known to be associated with thyroid dysfunction.

Patients involved in this study had primary or secondary atrial fibrillation diagnosed during a stay in hospital. Therefore, it is possible that the results from this study may not be generalizable to patients with atrial fibrillation who have not been admitted to hospital since the onset of the condition. However, the size of our study population and the unique design of a population-based study are strong advantages; therefore, the results of this study are robust and can inform clinical practice.

\section{Conclusion}

In this population-based study, we did not detect a difference between the effects of brand and generic formulations of amiodarone on the incidence of thyroid dysfunction. The results from this study provide valuable information for both clinicians and policy-makers concerning the prescription of brand-name versus generic drugs.

\section{References}

1. Roy D, Talajic M, Dorian P, et al. Amiodarone to prevent recurrence of atrial fibrillation. Canadian Trial of Atrial Fibrillation Investigators. N Engl J Med 2000;342:913-20.

2. Zarembski DG, Nolan PE Jr, Slack MK, et al. Treatment of resistant atrial fibrillation. A meta-analysis comparing amiodarone and flecainide. Arch Intern Med 1995;155:1885-91.

3. Taylor CJ, Hodgkinson J, Hobbs FD. Rhythm control agents and adverse events in patients with atrial fibrillation. Int J Clin Pract 2010;64:1069-75.

4. Martino E, Bartalena L, Bogazzi F, et al. The effects of amiodarone on the thyroid. Endocr Rev 2001;22:240-54.

5. Trip MD, Wiersinga W, Plomp TA. Incidence, predictability, and pathogenesis of amiodarone-induced thyrotoxicosis and hypothyroidism. Am J Med 1991;91:507-11.

6. Cairns JA, Connolly SJ, Roberts R, et al. Randomised trial of outcome after myocardial infarction in patients with frequent or repetitive ventricular premature depolarisations: CAMIAT. Canadian Amiodarone Myocardial Infarction Arrhythmia Trial Investigators. Lancet 1997;349:675-82.

7. Batcher EL, Tang XC, Singh BN, et al. Thyroid function abnormalities during amiodarone therapy for persistent atrial fibrillation. Am J Med 2007;120:880-5.

8. Hofmann A, Nawara C, Ofluoglu S, et al. Incidence and predictability of amiodarone-induced thyrotoxicosis and hypothyroidism. Wien Klin Wochenschr 2008;120:493-8.

9. Andersson K, Bergstrom G, Petzold MG, et al. Impact of generic substitution reform on patients' and society's expenditure for pharmaceuticals. Health Policy 2007;81:376-84.

10. Anis AH. Pharmaceutical policies in Canada: another example of federal-provincial discord. CMAJ 2000;162:523-6.

11. Benditt DG. Generic antiarrhythmic drugs: what constitutes equivalency. J Interv Card Electrophysiol 1999;3:145-7.

12. Reiffel JA. Issues in the use of generic antiarrhythmic drugs. Curr Opin Cardiol 2001;16:23-9.
13. Reiffel JA, Kowey PR. Generic antiarrhythmics are not therapeutically equivalent for the treatment of tachyarrhythmias. Am J Cardiol 2000;85:1151-3, A10.

14. Sauro SC, DeCarolis DD, Pierpont GL, et al. Comparison of plasma concentrations for two amiodarone products. Ann Pharmacother 2002;36:1682-5.

15. Pollak PT. Altered metabolite concentrations with amiodarone generic substitution cannot be observed without monitoring. Can J Cardiol 2001;17:1159-63.

16. Tamblyn R, Lavoie G, Petrella L, et al. The use of prescription claims databases in pharmacoepidemiological research: the accuracy and comprehensiveness of the prescription claims database in Quebec. J Clin Epidemiol 1995;48:999-1009.

17. Altman DR, Kuhne M, Sticherling C, et al. Use of the CHADS risk score to guide antithrombotic treatment in patients with atrial fibrillation - room for improvement. Swiss Med Wkly 2010;140:73-7.

18. Eskes SA, Wiersinga WM. Amiodarone and thyroid. Best Pract Res Clin Endocrinol Metab 2009;23:735-51.

19. Cohen-Lehman J, Dahl P, Danzi S, et al. Effects of amiodarone therapy on thyroid function. Nat Rev Endocrinol 2010;6:34-41.

20. Pazin-Filho A, de Jesus AM, Magalhaes PK, et al. How frequently should a patient taking amiodarone be screened for thyroid dysfunction? Braz J Med Biol Res 2009;42:744-9.

21. Kesselheim AS, Misono AS, Lee JL, et al. Clinical equivalence of generic and brand-name drugs used in cardiovascular disease: a systematic review and meta-analysis. JAMA 2008;300:2514-26.

22. Reiffel JA. Formulation substitution: a frequently overlooked variable in cardiovascular drug management. Prog Cardiovasc Dis 2004;47:3-10.

23. Ngo SN, Barnes T. Is there variability in drug release and physical characteristics of amiodarone chloride from different commercially available tablets? Possible therapeutic implications. Int $J$ Pharm Pract 2010;18:245-8.

24. Hollowell JG, Staehling NW, Flanders WD, et al. Serum TSH, T(4), and thyroid antibodies in the United States population (1988 to 1994): National Health and Nutrition Examination Survey (NHANES III). J Clin Endocrinol Metab 2002;87:489-99.

25. Surks MI, Hollowell JG. Age-specific distribution of serum thyrotropin and antithyroid antibodies in the US population: implications for the prevalence of subclinical hypothyroidism. J Clin Endocrinol Metab 2007;92:4575-82.

26. Mariotti S, Franceschi C, Cossarizza A, et al. The aging thyroid. Endocr Rev 1995;16:686-715.

27. Dimopoulou I, Ilias I, Mastorakos G, et al. Effects of severity of chronic obstructive pulmonary disease on thyroid function. Metabolism 2001;50:1397-401.

28. Okutan O, Kartaloglu Z, Onde ME, et al. Pulmonary function tests and thyroid hormone concentrations in patients with chronic obstructive pulmonary disease. Med Princ Pract 2004;13:126-8.

29. Karadag F, Ozcan H, Karul AB, et al. Correlates of nonthyroidal illness syndrome in chronic obstructive pulmonary disease. Respir Med 2007;101:1439-46.

Affiliations: From the Divisions of Internal Medicine and Clinical Epidemiology (Tsadok, Rahme, Behlouli, Pilote), McGill University Health Center, Montréal, Que.; the Department of Pharmacy Practice and Administration (Jackevicius, Joo), College of Pharmacy, Western University of Health Sciences, Pomona, Calif.; the Division of Cardiology (Essebag), McGill University Health Center, Montréal, Que.; the Divisions of Cardiology and Clinical Epidemiology (Eisenberg), Jewish General Hospital and McGill University, Montréal, Que.; the Division of Cardiology (Humphries), University of British Columbia, Vancouver, BC; Institute for Clinical Evaluative Sciences (Tu), Toronto, Ont.

Contributors: Meytal Tsadok, Cynthia Jackevicius, Elham Rahme and Louise Pilote were involved in the conception and design of the study. Meytal Tsadok, Cynthia Jackevicius, Hassan Behlouli and Louise Pilote drafted the manuscript. Meytal Tsadok, Cynthia Jackevicius, Elham Rahme, Hassan Behlouli and Louise Pilote analyzed and interpreted the data. Meytal Tsadok, Cynthia Jackevicius, Vidal Essebag, Mark Eisenberg, Karin Humphries, Jack Tu, Jennifer Joo and Louise Pilote reviewed the manuscript. All of the authors had full access to the data, and all of the authors approved the final version of the manuscript submitted for publication.

Funding: Financial support for this study was provided by an operating grant from the Canadian Institutes of Health Research (grant number MOP-84304). 